\title{
Topics in Lead-Free Solders: Restriction of Hazardous Substances Recast (RoHS2)
}

\author{
SRINIVAS CHADA ${ }^{1,2}$ \\ 1.-Schlumberger HFE, Sugar Land, TX 77478, USA. 2.-e-mail: drschada2003@yahoo.com
}

The legislated ban on $\mathrm{Pb}, \mathrm{Cd}, \mathrm{Hg}$, Cr-VI, polybrominated biphenyl (PBB), and polybrominated diphenyl ether (PBDE) in electrical and electronic equipment was implemented throughout the European Union (EU) by Restriction of Hazardous Substances (RoHS) directives ${ }^{1}$ in Electrical and Electronic Equipment (EEE), while "Management Methods for Prevention and Control of Pollution from Production of Electronic and Information Products"2 was drafted by China. In the United States, California $^{3}$ legislated electronic waste recycling but not a total ban on lead in electronics. However, the EU repealed the initial directive on 2 January 2013 and replaced it with Directive 2011/65/EU/00. This new RoHS2 ${ }^{4}$ focuses on controlling EEE waste by simplifying and harmonizing with EU legislation so as to make it easily enforceable while increasing the legal clarity. Also, medical devices, monitoring and controlling instruments, and several sundry areas are no longer exempt. Significantly, Conformité Européenne marking and declaration of conformity are mandatory as of 3 January 2013, and the use of prior "green" and "no-lead" labels was totally scrapped. In accordance with the aforementioned legislations, the Electronic Packaging and Interconnection Materials (EPIM) Committee of the TMS Electronic, Magnetic $\&$ Photonic Materials (EMPMD) Division organized a series of successful symposia on lead-free and leadbearing solders in the past few years. The symposia were held at TMS annual and fall meetings, and the results were published ${ }^{5-18}$ in $J O M$ and special issues of the Journal of Electronic Materials (JEM). Continuing the trend, the recent " $\mathrm{Pb}$-free Solders and Emerging Interconnect and Packaging Technologies" symposium held 3-7 March 2013 at the TMS Annual Meeting in San Antonio, TX attracted a large number of participants. At the symposium organized by Nikhilesh Chawla et al., more than 49 papers and 22 posters dealing with next generation packaging, whisker growth, alloy and microstructural development, thermomechanical behavior, electromigration, processing, and reliability for lead-free solders were presented. The two papers selected for this issue of $J O M$ deal with Sn whisker growth, and solder joint reliability in lead-free solders.

Pure Sn finish is an economical way of replacing $\mathrm{Sn}-\mathrm{Pb}$ solders on lead-frames, but plated pure $\mathrm{Sn}$ can nucleate and grow whiskers and hillocks that are detrimental to the reliability of the devices and printed circuit board assembly. In the first paper, "A Predictive Model for Whisker Formation Based on Local Microstructure and Grain Boundary Properties," P. Sarobol et al. discuss local microstructural characteristics along with predictive models that promote whisker growth.

The second paper, "Characterization of Solder Joint Reliability Using Cyclic Mechanical Fatigue Testing," by C. Kim et al. is a review of cyclic bend fatigue and shear fatigue mechanisms that induce solder failure in electronics packages. The authors used numerical simulations applied to $\mathrm{Sn}-\mathrm{Pb}$ and $\mathrm{Pb}$-free solders to show the effect of most important factors such as chip geometry, solder mask, etc. on the failure mode.

\section{REFERENCES}

1. Industry Council for Electronic Equipment Recycling, Rivington Street, London. http://www.icer.org.uk.

2. "Management Methods for Prevention and Control of Pollution from Production of Electronic and Information Products," English translation of draft comments for China ROHS (July 2003).

3. Electronics Waste Recycling Act of 2003 (California S.B. 20/ 50). www.calrecycle.ca.gov/electronics/act2003/.

4. RoHS2 Directive 2011/65/EU of the European Parliament and of the Council of 8 June 2011 on the Restriction of the Use of Certain Hazardous Substances in Electrical and Electronic Equipment (recast), Off. J. Eur. Union (1 June 2011). http://eurlex.europa.eu/LexUriServ/LexUriServ.do? uri=OJ:L:2011:174:0088:0110:en:pdf.

5. Special Issue on Packaging and Soldering Technologies for Electronic Interconnects, J. Electron. Mater. 29, 1111 (2000).

6. Lead-Free Solders Section, JOM 53 (6), 16-41 (2001).

7. Special Issue on Lead-Free Solder Materials and Soldering Technologies, J. Electron. Mater. 30, 1049 (2001).

8. Lead-Free Solders Section, JOM 54 (6), 25-40 (2002).

9. Special Issue on Lead-Free Solders and Processing Issues in Microelectronic Packaging, J. Electron. Mater. 31, 1129 (2002). 
10. Lead-Free Solder Section, JOM 55 (6), 49-69 (2003).

11. Special Issue on Lead-Free Solders and Processing Issues in Microelectronic Packaging, J. Electron. Mater. 32, 1359(2003).

12. Lead-Free Solder and Microelectronics section, JOM 56 (6), 33-54 (2004).

13. Special Issue on Lead-Free Solders and Processing Issues in Microelectronic Packaging, J. Electron. Mater. 33, 1411 (2004).

14. Special Issue on Lead-Free Solder Implementation: Reliability, Alloy Development, New Technology, J. Electron. Mater. 35, 2073 (2006).
15. Special Issue on Pb-Free Electronic Solders: Alloy Design, Characterization, and Service Reliability, J. Electron. Mater. 37, 1 (2008).

16. Special Issue on Emerging Interconnect and Packaging Technologies, J. Electron. Mater. 38, 209 (2009).

17. Special Issue on Pb-Free Solders, J. Electron. Mater. 38, 2427 (2009).

18. Special Issue on Pb-Free Solders and Emerging Interconnect and Packaging Technologies, J. Electron. Mater. 39, 2503 (2010). 